\title{
FORMAÇÃO CONTINUADA DE \\ PROFESSORES: UM OLHAR A PARTIR \\ DO IMAGINÁRIO SOCIAL
}

\author{
CONTINUING EDUCATION OF \\ TEACHERS: A LOOK FROM THE \\ SOCIAL IMAGINARY
}

\author{
Ionice da Silva Debus ${ }^{1}$ \\ Valeska Fortes de Oliveira ${ }^{2}$
}

\begin{abstract}
Resumo: Este texto parte de uma pesquisa realizada com o objetivo de investigar e refletir sobre as significações imaginárias dos professores acerca da formação continuada. Para esse estudo, foram convidadas professoras que haviam participado de uma proposta de formação continuada construída em parceria entre o Grupo de Estudos e Pesquisas em Educação e Imaginário Social (GEPEIS) e uma Escola Estadual de Ensino Fundamental de Santa Maria (RS). Foram realizadas entrevistas orais semiestruturadas para, a partir das narrativas, organizar possíveis análises e interpretações. Os resultados mostram a importância das parcerias para a efetivação da formação continuada, a necessidade de os docentes se perceberem como um grupo que precisa coesão em busca de um objetivo comum, neste caso, a formação, bem como a relevância de o professor conhecer as questões externas e internas que interferem na formação, para, depois, buscar contorná-las. Pôde-se concluir que esse olhar para um programa de formação continuada resultante de parceria escola-universidade possibilitou a reflexão de ambas as partes sobre toda a dinâmica e complexidade existente nesse meio, salientando, ainda, a importância do estreitamento das relações entre as instituições em prol da formação e da Educação.
\end{abstract}

Palavras-chave: Formação continuada de professores. Imaginário Social. Saberes docentes. 
Summary: This text part of a survey conducted with the objective to investigate and reflect on the imaginary meanings of teachers about continuing education. Were invited to participate teachers who had participated in a continuing education proposal constructed in partnership between GEPEIS - Group of Studies and Research in Social Education and Imaginary, and a State School Elementary School Santa Maria (RS). Oral interviews were conducted semi-structured, to the narratives, interpretations and analyzes possible. The results show the importance of partnerships for effective continuing education, the need for teachers perceive themselves as a group for cohesion in pursuit of a common goal, in this case, the training, the importance of teacher knowledge and external issues interfering in internal training, to get around them. It can be concluded that a look at a continuing education program resulting in a school-university partnership, enabled reflection on both sides of all the dynamics and complexity existing in that environment and stressed the importance of strengthening relations between the institutions in favor training and education.

Keywords: Continuing education for teachers. Social Imaginary. Knowledge teachers. 


\section{Introdução}

Este trabalho surge de uma pesquisa intitulada "O Imaginário Social dos professores e a formação continuada”, realizada a partir de um olhar singular para uma proposta de formação continuada, sob a ótica do Imaginário Social de Castoriadis (1982). Na ocasião, foi feita uma parceria entre o Grupo de Estudos e Pesquisas em Educação e Imaginário Social (GEPEIS), da Universidade Federal de Santa Maria, coordenado pela Prof ${ }^{\mathrm{a}}$. Dr ${ }^{\mathrm{a}}$. Valeska Fortes de Oliveira, e uma escola da rede estadual, do mesmo município.

Durante a vivência dessa proposta de formação continuada, surgiram vários questionamentos a respeito da temática. Entre eles: quais as significações imaginárias dos professores acerca da formação continuada? Quais os motivos que levam os professores a buscá-la? Como essa formação interfere ou modifica a sua forma de agir?

Conhecer as significações dos professores acerca da formação continuada, principalmente no meio acadêmico da universidade, que é de onde partem algumas destas propostas de formação, é de total relevância, pois vai enriquecer a reflexão sobre o assunto e dispensar maior cuidado no preparo das atividades. Atualmente se fala bastante em formação, mas poucas mudanças reais são percebidas na prática do dia a dia, na sala de aula. Essa realidade indica a importância de se pensar uma proposta realmente significativa, a partir da qual esses educadores construam com qualidade seus instrumentais e suas formas de abordagem, para que resulte daí mais sucesso na sua ação profissional. É imperioso, pois, problematizar quais são as significações imaginárias dos professores acerca da formação continuada.

As propostas de formação continuada precisam estar de acordo com as demandas atuais desses professores. Corroborando o que afirma Pimenta (1999, p. 21): 
[...] a necessidade de se formar profissionais capazes de ensinar em situações singulares, instáveis, incertas, carregadas de conflitos e de dilemas, que caracteriza o ensino como prática social em contextos historicamente situados.

Salienta-se, portanto, a importância da formação continuada pensada numa perspectiva crítica, que não se reduza a treinamento, mas que seja significativa o suficiente para transformar a prática de ensino e o resultado. Desta pesquisa, os objetivos principais são conhecer as significações imaginárias desses professores acerca da formação continuada, o que os motivam e o que esperam dela, bem como contribuir na teorização da temática formação de professores.

\section{Como tudo começou...}

A coordenadora e algumas pessoas do Grupo se dispuseram a planejar um programa de formação continuada para professores. Quem se manifestou interessada foi a Escola Estadual de Ensino Fundamental Marieta D’Ambrósio, localizada no centro da cidade de Santa Maria (RS), educandário que atende a um público discente bem diverso, oriundo de diferentes classes sociais. O corpo docente é formado por professores que estão há algum tempo na instituição e outros que acabam de chegar.

Essa instituição é uma típica escola pública, como tantas outras, com todos os novos desafios que existem nesse ambiente diverso. Corroborando a afirmativa de Ferreira e Eizirik:

A escola demanda novas leituras, tanto na sua concepção como no conhecimento que temos das relações ensino- 
aprendizagem, dos sistemas de vínculos, dos micro e macroprocessos que reproduzem e/ou são produzidos pelos discursos e práticas pedagógicas. (FERREIRA; EIZIRIK, 1994, p. 6).

Ao falar de escola, não se está pensando somente na instituição como espaço físico, mas em um ambiente amplo, onde há todo um conjunto de relações e sentidos que, manifestos ou não, fazem parte desse todo. A partir desse olhar mais sensível, procurou-se perceber as dúvidas, angústias, sonhos e diferentes pontos de vista das pessoas e entender melhor muitas questões que surgem nessas relações.

Nesse Programa de Formação Continuada, que se desenvolveu do dia 12 de abril ao dia 27 de setembro de 2008, ocorreram dez encontros, realizados na própria escola. É importante ressaltar que, paralelamente a eles, na Universidade, foram realizadas reuniões de avaliação entre o GEPEIS e algumas professoras, nas quais essas participantes traziam impressões do trabalho que estava sendo realizado e, depois, elaboravam sugestões para os encontros posteriores.

Nesses encontros avaliativos, começaram a surgir algumas questões. A partir dos relatos das professoras, era possível perceber a dificuldade em manter o grupo inicial instigado/ motivado a continuar participando. Começando pela dificuldade de acertar um horário em que a maioria pudesse comparecer até chegar a um acordo quanto aos temas dos encontros.

Surge, também, a relevância de procurar investigar como se dá essa formação, que assuntos, que temas, o que realmente mobiliza esses professores nessa busca e o que pode ser feito por parte de quem pensa esses programas, principalmente para a Universidade, de onde partem alguns desses docentes. 


\section{Metodologia}

A metodologia da pesquisa constituiu-se do percurso que foi seguido para alcançar os objetivos propostos. De acordo com Minayo (1994, p. 16), “[...] o sentido generoso de pensar a metodologia como a articulação entre conteúdos, pensamentos e existência." Partindo disso, foi delineado um caminho de investigação embasado nas concepções teóricas escolhidas.

Essa pesquisa foi de cunho qualitativo, por ter sido o lugar da intuição, da exploração e do subjetivismo (MINAYO, 1994). Neste sentido, foram buscadas as significações sobre o espaço formativo dos sujeitos envolvidos, onde essa abordagem aprofunda-se no mundo dos significados das ações e relações humanas, um lado não perceptível e não captável em equações e estatísticas (MINAYO, 1994, p. 22).

O procedimento metodológico utilizado foi o estudo de caso, que objetiva responder à questão principal da pesquisa - "Quais as significações imaginárias dos professores acerca da formação continuada?" - e, a partir desta, chegar a algumas considerações.

Para tanto, o contexto em que ocorreu a formação dos docentes, considerando sua complexidade e subjetividade, foi investigado por meio de entrevistas com os professores, com a intenção de proporcionar o conhecimento de um grupo específico e de sua subjetividade e identificar possíveis fatores que a influenciaram. Foram convidados a participar dessa pesquisa professores que tinham participado da proposta de formação continuada pensada pelo Grupo de Estudo e Pesquisas em Educação e Imaginário Social (GEPEIS), juntamente com a Escola Estadual de Ensino Fundamental Marieta D’Ambrósio, de Santa Maria.

As técnicas utilizadas nessa pesquisa buscaram, por intermédio de narrativas, a sistematização das significações 
imaginárias dos professores acerca da formação continuada. A coleta de dados ocorreu em duas dimensões, uma bibliográfica e outra empírica. Optou-se por trabalhar nessas duas dimensões por possibilitarem um diálogo entre os estudos do Imaginário Social e as narrativas dos colaboradores. Para tanto, foram trazidos estudos nas temáticas do Imaginário Social, na perspectiva de Cornelius Castoriadis (1982), Ferreira e Eizirik (1994) e Nilda Teves (1992), Valeska Fortes de Oliveira (2004), bem como de formação de professores com Selma Garrido Pimenta (1999), Maurice Tardif (2002), Moreira (2002), entre outros.

Simultaneamente à pesquisa bibliográfica, foram realizadas entrevistas orais semiestruturadas, como parte empírica da coleta de dados. Traziam algumas questões previamente formuladas, no intuito de buscar as significações imaginárias dos sujeitos referentes ao tema escolhido.

$\mathrm{Na}$ Universidade Federal de Santa Maria, toda e qualquer pesquisa que envolva seres humanos deve ser submetida à aprovação do Comitê de Ética e Pesquisa. Entendendo a importância da reflexão ética acerca do projeto, a pesquisa somente foi iniciada após a sua liberação pelo Comitê de Ética.

Foram convidadas três professoras que participaram do Programa de Formação Continuada, com o intuito de captar a posição delas em relação ao assunto. Como esse trabalho traz olhar singular para uma proposta de formação continuada, tomou-se a liberdade de escolher os pseudônimos para as professoras voluntárias da pesquisa. Após a observação das características de cada uma, surgem: A Artista, assim chamada, carinhosamente, porque é autora de lindas peças de artesanato, que alegram seu ambiente de trabalho; A Poetisa, pela criatividade e inspiração que imprime nas suas obras literárias; e Sol, que sempre contagiava a todos com sua disponibilidade e seu sorriso radiante. 
A Artista tem alguns anos de magistério e, há pouco mais de um ano, faz parte da equipe gestora dessa escola. Desde que chegou, mostrou-se uma pessoa comprometida com o que faz, com facilidade para trabalhar em grupo e agregar pessoas em prol de um objetivo comum. Mesmo estando quase em tempo de se aposentar, empenha-se cada vez mais, acreditando na Educação e no papel importante de cada um dentro da instituição e mantendo entusiasmo contagiante, características percebidas durante a entrevista e nas suas atitudes.

A Poetisa está na profissão há poucos anos e já demonstra que acredita que é possível uma educação melhor e deposita confiança na importância do professor para conseguir o que se almeja. Desde o início da proposta de formação, mostrou-se muito interessada e participativa, trazendo para si a responsabilidade, muitas vezes, de ser porta voz dos outros professores.

"Entre sonho e realidade

Existem diferenças

Em se tratando de poesia

Tudo pode ser verdade.

Primeiro, é brincar com palavras

Para um escritor formar.

E na História brilhar." (VARGAS, 2009, p. 70)

A professora Sol também já tem alguns anos de profissão e, atualmente, faz parte da equipe gestora da escola. Acredita que é possível a mudança e, cada vez mais, melhorar a escola, não medindo esforços para isso, sempre sorridente e com boa vontade.

Com os dados coletados em mãos, passou-se à análise e interpretação, utilizando uma abordagem hermenêutica, em que as respostas às questões formuladas devem articular-se ao 
contexto cultural do qual faz parte (MINAYO, 1994, p. 69). Esta abordagem leva em consideração o contexto sócio-histórico dos indivíduos, indo ao encontro da teoria do Imaginário Social, no momento em que esta defende a criação de redes simbólicas pelos indivíduos de um determinado contexto social (CASTORIADIS, 1982).

A análise foi realizada por um entrelaçamento entre os dados coletados empiricamente e os obtidos por meio dos referenciais teóricos na intenção de alcançar os objetivos propostos. Daí, alguns resultados surgem, mas não como absolutos.

\section{Significados e sentidos construídos sobre formação continuada}

Falar de formação não é tarefa muito fácil, principalmente, quando se trata de um grupo de professores, considerando que nem todos têm as mesmas percepções e nem dão os mesmos sentidos ao que vivenciam. É neste momento que o Imaginário Social tem um grande papel, pois leva em conta, além dos aspectos físicos e materiais das instituições, também a dimensão simbólica, procurando uma abordagem mais complexa da questão (FERREIRA; EIZIRICK, 1994).

Para tanto, é necessário um olhar mais sensível que consiga captar essas significações imaginárias. Segundo Castoriadis (1982, p. 177):

O papel das significações imaginárias é tentar dar uma resposta a algumas perguntas fundamentais que toda a sociedade se faz: quem somos nós como coletividade? Que somos nós uns para os outros? Onde e em que somos nós? Que queremos? Que desejamos e que nos falta? 
Mesmo aqueles professores que optam por não participar ativamente de um Programa de Formação Continuada têm algo a dizer, estão demonstrando algo com sua escolha, denunciando suas próprias concepções sobre a formação por intermédio de suas ações.

Para aqueles que participam, a questão é mais ampla do que simplesmente estar presente nos encontros de formação, pois, além de se dispor a ir, a pessoa precisa tornar significativo para ela tudo o que acontece nesse espaço, para criar um processo real de mudança, tanto em termos conceituais, relacionadas à sua posição em relação ao assunto, quanto em termos pessoais, interiores, para realmente transformar sua ação.

É, pois, impossível pensar a complexidade de uma proposta de formação continuada sem um olhar sensível, que possa dar conta de toda subjetividade que permeia as relações aí existentes. É no Imaginário Social que se encontra um caminho possível, que busca nas expressões todos os sentidos, concordando com Ferreira e Eizirik, quando dizem que:

São formas de expressão que nos remetem ao campo do dizível e do indizível, do óbvio e do mistério, do visível e do invisível, dos sonhos e dos desejos, do conhecimento e da ação. Apreender seus sentidos significa percorrer caminhos sinuosos, na busca de 'decifração' daquilo que se mostra/ocultando. Pode-se dizer que o Imaginário Social não se institui, enquanto objeto de conhecimento, de tal forma que possamos identificá-lo por procedimentos imediatos. Investigá-lo significa adentrar pelas vias das linguagens, admiti-lo como algo que se institui/instituindo sentido à vida humana. (FERREIRA; EIZIRIK, 1994, p. 9).

Então, a partir da percepção e da leitura de gestos, cores, sons, sabores, corpos, objetos, palavras, estilos, surgem alguns 
elementos importantes a serem considerados, tanto para quem os vivencia como para quem os lê, como um recurso para entender muitas questões e, se necessário e possível, transformar realidades.

Neste caso, existem questões que podem ser observadas e consideradas ao serem pensadas propostas de formação continuada, claro que considerando cada realidade específica, mas, de alguma forma, podem ser muito úteis para obter resultados positivos e alcançar os objetivos almejados, como as que seguem abaixo.

\section{As parcerias na formação continuada}

Uma questão importante percebida é em relação às parcerias na formação continuada, levando em conta que, segundo o dicionário (SCOTTINI, 2009), parceria significa sociedade, reunião de indivíduos com interesse comum, pois, como demonstram as professoras, são as parcerias que dão o diferencial para a efetivação da formação.

Assim, a importância atribuída às parcerias demonstra a necessidade que os professores têm de algo que lhes instigue a reflexão sobre o seu trabalho e auxilie na visão do todo da escola e dos problemas que precisam ser solucionados. Neste sentido, as propostas de formação continuada precisam estar de acordo com as demandas, por isso a relevância de se conhecer, cada vez mais a fundo, o que pensam, o que querem e o que leva os professores a buscarem tal formação. Esta relação de proximidade na formação de professores torna-se um aspecto importante da parceria entre universidade e escola. 
Tá, então, assim, eu vejo que essas parcerias que a gente procura fora da escola, ela proporciona a gente fazer uma formação um pouco mais fundamentada, porque daí a universidade trabalha com a formação, com as questões teóricas, e às vezes a gente fica muito na prática do dia a dia e não se dá conta dessas questões, das leituras, eu acho que as parcerias vêm contribuir um pouco com isso e também no sentido assim de organizar porque daí quando tu tem parcerias tem uma visão sobre o grupo e tu tem outra visão e daí junto consegue formar uma coisa só, às vezes uma ideia que tu não pensou no memento surge ali na conversa, no diálogo com o grupo, tem uma outra visão, é uma outra vivência, uma outra situação que trata dentro da escola,que pode ajudar ou não, às vezes atrapalha. (A Poetisa).

Esse esforço conjunto relacionado à formação do professor é uma necessidade marcante na fala. Corroborando essa premissa, Marques (2000) assegura que:

Todas as instituições responsáveis pela educação devem ser envolvidas nos processos da formação continuada do educador. Cumpre, no entanto, dediquemos aqui atenção especial às responsabilidades específicas da universidade. Deve a ele dar continuidade e propiciarlhe as rupturas exigidas pelo exercício da profissão na concretude das exigências renovadas. Importa assuma como atribuição sua tanto os estágios da formação inicial como os da formação continuada dos educadores, mesmo porque não podemos cumprir uma das tarefas sem a outra. (MARQUES, 2000, p. 209).

As Instituições Públicas de Educação e Ensino devem ser percebidas como locais onde é possível, ao professor, acionar mecanismos de reflexão sobre as escolhas, os desejos, as 
expectativas e as motivações que impulsionam sua trajetória profissional, bem como reconhecer as interações e vivências cotidianas educativas como constituintes dos processos de formação continuada. Esse espaço deve propiciar a reflexão sobre os saberes, experiências e outros saberes e conhecimentos necessários à docência.

As práticas de formação continuada que geralmente acontecem são cursos, seminários, palestras, enfim, eventos de curta duração, pensados e organizados por alguém alheio à escola, sem a reflexão crítica da prática pedagógica daquela realidade. Dar voz aos professores, saber de suas dúvidas, angústias, desejos, são procedimentos que têm constituído o diferencial quando se pensa alguma proposta de formação.

Para que tenham esse alcance, as práticas de formação devem buscar a participação direta de todos os envolvidos, tanto no planejamento, quanto na execução e na avaliação das atividades desenvolvidas para que todos possam significar esse processo ao máximo e infundir real mudança no seu cotidiano. Partindo das necessidades específicas de cada escola e levando os professores a refletirem sobre sua prática e se identificarem com a profissão, pode ser um trabalho que oportunize a esses sujeitos o reconhecimento de que sua experiência, pode ser, efetivamente, um saber.

As parcerias são importantes no momento em que buscam pensar uma proposta adequada a cada realidade, ouvindo e envolvendo os sujeitos em todos os momentos, desde a escolha das temáticas até a avaliação final de todo o trabalho, na intenção de aperfeiçoamento constante.

Essa importância não está relacionada somente aos professores ou à escola que busca, mas, também, às instituições, que têm a oportunidade de estar em contato com o cotidiano escolar, fazendo relação mais direta da teoria da academia com a prática do dia a dia desses professores, auxiliando-os nas reflexões. Concordando com Pimenta: 
A formação de professores na tendência reflexiva se configura como uma política de valorização do desenvolvimento pessoal-profissional dos professores e das instituições escolares, uma vez que supõe condições de trabalho propiciadoras da formação como contínua dos professores, no local de trabalho, em redes de autoformação, e em parceria com outras instituições de formação. (PIMENTA, 1999, p. 31).

Então, essa troca entre escolas e instituições de formação se apresenta como grande diferencial para a formação continuada, pois possibilita uma busca conjunta, onde ambas as partes têm oportunidade de aperfeiçoamento, tanto profissional quanto pessoal, por meio das trocas de saberes e experiências que permeiam esse espaço.

\section{A escola como grupo}

Considerando que grupos são constituídos por pessoas que buscam um objetivo comum e, por isso, estão ligadas entre si (GAYOTTO, 2001), a escola não poderia deixar de ser caracterizada como tal. Desde que começaram os encontros, foi possível observar a dinâmica grupal em diferentes papéis, de acordo com a distribuição das tarefas e as representações individuais.

A escola é vista como um grupo não somente em relação à proposta de formação, mas, também, no seu cotidiano. Conforme as falas das entrevistadas:

A gente trabalhou bastante esta questão das relações interpessoais dentro do grupo, para que o grupo realmente se concentrasse como grupo e não fossem apenas pessoas 
que trabalhavam no mesmo lugar. Eu acho que isso é bem importante quando se fala em Educação, que as pessoas têm que ter minimamente uma relação entre elas, porque são os contratos pessoais que a gente assina e o próprio comprometimento só nasce no momento em que o outro tem significado para mim. (A Artista).

Então, perceber a escola como grupo é um passo importante para a qualidade da educação, pois o envolvimento das pessoas é um diferencial, como aponta Pichon-Riviére:

Grupo é um conjunto de pessoas que, ligadas por constantes de tempo e espaço e articuladas por sua mútua representação interna, se propõe de forma explícita e implícita a uma tarefa, que constitui sua finalidade, interatuando através de complexos mecanismos de assunção e atribuição de papéis. (PICHON-RIVIẼRE, 1998, p. 169).

Assim, cada sujeito de um grupo atribui a si um papel na dinâmica grupal, não sendo estático, mas mutável, de acordo com a distribuição das tarefas e representações individuais. Desta forma, entender essa dinâmica e a distribuição desses papéis é fundamental para se conhecer um grupo e a sua principal função para os sujeitos, neste caso, o grupo de professores.

\section{Formação a partir do sujeito: questões internas e externas}

Outro ponto importante levantado pelas professoras está relacionado às questões internas e externas que interferem na efetivação ou até mesmo na qualidade da formação. No aspecto externo, estão a falta de incentivo e desinteresse por parte do 
governo, o grande número de aposentadorias e a desvalorização por parte da sociedade.

Aí eu sinto novamente a questão das professoras, de desfavorável a questão das aposentadorias, as professoras que já estão assim cansadas, querendo sair e já não se dedicam, já não participam e ao mesmo tempo tem a chegada de novas colegas surpreendentemente este ano elas chegaram com um gás novo, um ânimo novo e principalmente a gente vê isso no currículo, que trouxe uma energia positiva, melhor, de colegas assim que vieram agregar o trabalho da nossa escola. (Sol).

Cabe salientar que o desinteresse por parte do governo não se configura como um fato observado somente nessa proposta específica de formação continuada. Se forem observados cursos e palestras oferecidos para os professores e a importância que dão aos fins burocráticos, entende-se que é, praticamente, generalizado rotular a formação continuada como algo somente para constar.

O grande número de aposentadorias é outro aspecto que aparece nas entrevistas como algo que dificulta a formação, pois muitos professores já com tempo para encaminhar pedido de aposentadoria, não têm o mesmo interesse em participar das propostas de formação. Esse é um problema concreto, externo, que desestimula os professores de se mobilizarem na busca pela formação, talvez, também, pela falta de incentivo do governo.

A desvalorização da profissão docente por parte da sociedade é outro ponto que é externo, mas que influencia nos sentidos e significados que os professores dão à sua profissão e que, muitas vezes, precisam ter cuidado para não interiorizar e conseguir fugir dos rótulos que lhes dão, como aponta Moreira (2002): 
O professor, apesar de todas as limitações e faltas de algumas condições básicas para realizar o seu trabalho, precisa conquistar um "novo patamar profissional". $\mathrm{Ou}$ seja, deve (re)conquistar apoio e prestígio da sociedade em geral e dos gestores educacionais, para que compreendam que ele, o professor não é o único responsável pela chamada insuficiência das aprendizagens dos alunos, e que a qualidade da formação do professor e o contexto institucional interferem diretamente nos resultados do seu trabalho. (MOREIRA, 2002, p. 45).

Em relação ao interno está a questão da motivação e a desvalorização do próprio professor. Neste sentido, precisa partir dele o desejo de mudança e de busca por aquilo que lhe falta.

Para mim, o bom programa de formação continuada é aquele em que os sujeitos estão mobilizados, porque daí eles buscam e aí a gente vai organizar de acordo com esta busca, este desejo, essa questão do desejo a gente vê falar a muito tempo dentro da atividade pedagógica, sem desejo não há condição e como desejo não é algo que possa ser ensinado nem comprado, e nem eu posso acionar meu próprio desejo, é quando a gente tem um conjunto de elementos que fazem com que o desejo surja então eu acho que um bom programa de formação continuada é esse, que a mobilização aconteça pra fazer acontecer o desejo. (A Artista).

Essa questão de ir ao encontro do que falta ou de superar o que desestabiliza é individual e depende de cada um, que possui suas próprias vivências e interpreta a si mesmo de maneira única.

Então, fica salientada a importância para o professor do conhecimento de si, de suas necessidades, seus anseios, para saber onde encontrar respostas para essas questões. Também é necessária a percepção de todos os fatores que podem influenciar na bus- 
ca e no encontro dessas respostas, sabendo identificar as questões internas e externas, para melhor trabalhá-las e vencê-las.

\section{Algumas considerações: concebendo a formação como contínua}

Diante dos resultados obtidos, algumas considerações surgem - não como definitivas e absolutas, pois, se tratando de Educação, são vários os sentidos e significados construídos diante das trajetórias formativas dos sujeitos.

Com tudo que foi dito, ouvido, sentido, compartilhado, o que fica é o entrelaçamento das trajetórias formativas dos sujeitos. No momento em que o pesquisador busca os sentidos da formação para os sujeitos da sua pesquisa, estes outros ativam nele a necessidade de entendimento de sua própria trajetória, tornando-o pesquisador de si. Surge, pois, um olhar cuidadoso para a formação, tanto profissional quanto pessoal de todos os envolvidos, na intenção de encontrar respostas aos questionamentos.

Como foi possível perceber, os diferentes sujeitos dão sentidos e significados também diferentes à formação, porém alguns aspectos se tornam relevantes, como é o caso da importância das parcerias na formação continuada. Elas são importantes no momento em que possibilitam a troca de experiências, o envolvimento de todos, a construção de propostas adequadas para cada realidade específica, bem como a ligação direta da teoria com a prática.

Também, surge a importância de se pensar a escola como grupo, em que os sujeitos se percebam a ele pertencentes, havendo, entre eles, atribuição de papéis, alimentando a dinâmica grupal e permitindo maior envolvimento em prol da tarefa, neste caso, a formação continuada. 
As questões internas e externas que interferem na qualidade da formação são aspectos importantes a serem observados; entre eles, as necessidades, os anseios, os desejos desses professores, bem como o descaso por parte do governo e da sociedade. Detectar e trabalhar contra essas interferências são tarefas que assumem grande relevância para quem pensa e vivencia a formação.

Diante do constatado, variadas são as condições que interferem na efetivação de uma proposta de formação continuada, por isso a relevância de se conhecer e refletir sobre essas condições e conhecer o que realmente querem e buscam esses profissionais que estão no cotidiano das salas de aula e das escolas. Cabe, neste caso, à universidade atentar para esses resultados e pensar em propostas que possibilitem espaços de reflexão coletiva em busca do aperfeiçoamento constante das práticas educativas. Corroborando o pensamento de Marques (2000):

Todas as instituições responsáveis pela educação devem ser envolvidas nos processos da formação continuada do educador. Cumpre, no entanto, dediquemos aqui, atenção especial às responsabilidades específicas da universidade. Escola da educação do educador, à universidade não é atribuído apenas o processo formativo formal. Deve a ele dar continuidade e propiciar-lhe as rupturas exigidas pelo exercício da profissão na concretude das exigências renovadas. Importa assuma como atribuição sua tanto os estágios da formação inicial como os da formação continuada dos educadores, mesmo porque não poderia cumprir com uma das tarefas sem a outra. (MARQUES, 2000, p. 209).

Assim, um olhar para um programa de formação continuada resultante de parceria entre escola-universidade, possibilitou a reflexão sobre toda a dinâmica e complexidade existente 
nesse meio e salientou a importância do estreitamento entre as instituições em prol da Educação.

Pode ser apenas um indício, mas pode, também, ser o ponto desencadeador de várias outras e mais profundas buscas, produtoras de resultados que revolucionem a ação dos que se entregam a essa causa, que deveria ser de todos.

\section{Referências}

CASTORIADIS, Cornelius. A instituição imaginária da sociedade. Rio de Janeiro: Paz e Terra, 1982.

GAYOTTO, Maria Leonor Cunha (Org.). Trabalho em grupo: ferramenta para mudança. Petrópolis, RJ: Vozes, 2001.

MARQUES, Mario Osório. A formação do profissional da educação. Ijuí: Ed. Unijuí, 2000.

. Projeto pedagógico: a marca da escola. Revista Contexto e Educação. Ijuí: Unijuí, p. 16-28, 1986.

MINAYO, Maria Cecília de Souza (Org.). Pesquisa Social: teoria, método e criatividade. Petrópolis, RJ: Vozes, 1994.

MOREIRA, Carlos Eduardo. Formação continuada de professores: entre o improviso e a profissionalização. Florianópolis: Insular, 2002.

NÓBREGA, Francisca. O processo coletivo de imaginar. In: TEVES, Nilda (Org.). Imaginário social e educação. Rio de Janeiro: Gryphus, 1992.

NÓVOA, A. Os professores e sua formação. 2. ed. Portugal: Dom Quixote, 1995. 
OLIVEIRA, Valeska Fortes de. Imagens de professor: significações do trabalho docente. 2. ed. Ijuí, RS: Editora Unijuí, 2004.

PIMENTA, Selma Garrido (Org.). Saberes pedagógicos e atividade docente. São Paulo: Cortez, 1999.

; GHEDIN, Evandro (Orgs.). Professor Reflexivo no Brasil: gênese e crítica de um conceito. São Paulo: Cortez, 2002.

SCOTTINI, Alfredo. Minidicionário escolar da língua portuguesa. Blumenau, SC: Todolivro, 2009.

TARDIF, Maurice. Saberes docentes e formação profissional. Petrópolis, RJ: Vozes, 2002.

TEVES, Nilda (Org.). Imaginário social e educação. Rio de Janeiro: Gryphus, 1992.

VARGAS, Etiene da Silva de (Org.). Brilha, brilha poesia (poesias de oficina): coletânea infantil. Santa Maria: Pallotti, 2009.

\section{Notas}

1 Pedagoga. Mestranda em Educação pelo Programa de Pós-Graduação da Universidade Federal de Santa Maria (UFSM). E-mail: < nicedebus@hotmail. com>.

${ }^{2}$ Professora titular do Departamento de Fundamentos da Educação do Centro de Educação da Universidade Federal de Santa Maria (UFSM). Coordenadora do Grupo de Estudos e Pesquisas em Educação e Imaginário Social (GEPEIS). E-mail:<guiza@terra.com.br>. 